\title{
The Impact of Falls in the Elderly
}

Nicole D.A. Boyé, MD ${ }^{1,2}$, Esther M.M. Van Lieshout, PhD¹, Ed F. Van Beeck,

$\mathrm{PhD}^{3}$, Klaas A Hartholt, MD, $\mathrm{PhD}^{1,2}$, Tischa J.M. Van der Cammen, MD, $\mathrm{PhD}^{2}$, Peter Patka, MD, PhD ${ }^{4}$.

${ }^{1}$ Department of Surgery-Traumatology, ${ }^{2}$ Section of Geriatric Medicine, Department of Internal Medicine, ${ }^{3}$ Department of Public Health, and ${ }^{4}$ Emergency Department, Erasmus MC, University Medical Center Rotterdam, Rotterdam, The Netherlands

\section{Corresponding author}

Esther M.M. Van Lieshout, PhD

Erasmus MC, University Medical Center Rotterdam

Department of Surgery-Traumatology

PO Box 2040, 3000 CA Rotterdam

The Netherlands

Phone: +31 107031050

Fax: +31 107032396

E-mail: e.vanlieshout@erasmusmc.nl 


\section{Abstract}

The number of falls in the elderly is becoming a major public health problem in our society. In the past decade life expectancy increased from 75 years in 1990 to 79 years in 2009 in the United States (US). It has been estimated that the number of persons aged 65 years and older in the US will double by 2050 .

In 2000 falls accounted for $45 \%$ of all injury-related inpatient stays, with almost 750,000 hospitalizations. Fractures were the most common primary injury diagnosis, including 314,006 hip fractures. Injury following a fall is associated with a decreased quality of life and poor functional outcome, in severe injuries these effects continue for a prolonged period of time.

In 2006 fall-related medical costs in the population aged $\geq 65$ in the US amounted to US\$19 billion for non-fatal and US\$0.2 billion for fatal injuries. In this paper we provide a literature overview on the impact of falls in the elderly, the demands on healthcare and the costs for our society.

Keywords: Falls, injury, costs, older adults, quality of life, prevention. 


\section{Introduction}

The number of falls in the elderly is becoming a major public health problem in our society. In past decades life expectancy has risen from 77 years in 1990 to 81 years in 2009 in the Netherlands. Similar trends were noted in other countries; from 75 to 79 years in the US, and from 76 to 80 years in the UK. This gives an estimate of the increasing life expectancy in western countries worldwide (WHO, 2011). In 2010 Vincent et al. estimated that the number of persons aged 65 years and older in the US will double by 2050 (Vincent and Velkoff, 2010). In 201014 percent of the population in the US was 85 years or older, by 2050 that proportion is expected to increase to more than 21 percent. Currently 15.6 percent of the population in the Netherlands is aged 65 years or older; this is estimated to increase to 25 percent by 2050 (CBS, 2010).

How should we prepare our society for the growing number of elderly and the array of health problems associated with increased age? Approximately one out of three persons aged $\geq 65$ years experiences a fall every year (Tinetti et al., 1994). The most important risk factors for falls are old age ( $>80$ years), a history of falls, gait deficit, balance deficit, use of assistive device, visual deficit, arthritis, impaired activities of daily living (ADL), depression, and cognitive impairment. Other risk factors include the environment (e.g., insufficient lighting, 
rugs, and loose wiring), and comorbidities like orthostatic hypotension, vertigo, and Parkinson's disease (Tinetti et al., 1988, Nevitt et al., 1989, AGS/BGS, 2010, AGS/BGS/AAOS, 2001). Approximately 33 percent of persons over 65 years use so-called fall-risk-increasing drugs (FRIDs) such as cardiovascular and psychotropic drugs (Woolcott et al., 2009, Leipzig et al., 1999b, Leipzig et al., 1999a).

Low-level falls are deemed as fairly innocent in the young, yet falls in the older population are associated with substantial higher morbidity and mortality rates. This will put a substantial burden on healthcare workers and institutions, and will result in rising healthcare costs as long as the population of elderly continues to grow. In order to solve this public health problem we need insight into the outcome of falls in the older population, such as the type of injury, mortality, disability, fear of falling, and social isolation. Also, the burden of falls on healthcare systems including emergency departments (ED), hospitals, longterm care and rehabilitation facilities, and the costs of falls for our society and economy need to be investigated. Falls-prevention programs provided by healthcare givers are now being developed and implemented worldwide, assessing and managing risk factors for falls. In this paper we provide a literature overview on the impact of falls in the elderly, including predominant 
injuries following a fall, the quality of life after a fall, the costs of treatment, and the effectiveness of fall prevention.

\section{Burden on Healthcare}

In 2009 the number of persons aged 65 and older treated at an ED for a nonfatal fall in the US was 1,594,335 (CDC, 2004). Greenspan et al. showed that of all injury-related hospitalizations in 2000 , discharge rates from hospitals were highest for those aged 65 years and older; adults 85 years and older had the highest hospitalization rates of any age group $(5,499$ per 100,000$)$. Falls were the leading cause of hospitalization. With almost 750,000 hospitalizations, falls accounted for $45 \%$ of all inpatient stays. Fractures were the most common primary injury diagnosis, including 314,006 hip fractures (Greenspan et al., 2006).

Falls are also the leading cause of traumatic brain injury, between 2002 and 2006, an average of 144,338 persons aged $\geq 65$ sustained traumatic brain injury in the US annually, of which 107,221 visited the ED, 29,860 were hospitalized and 7,257 resulted in death (Faul, 2010).

In 2008 there were 34,091 fall related hospitalizations including 14,258 with hip fractures (Hartholt et al., 2010) and 3,010 with significant traumatic 
head injury (Hartholt et al., 2011c) in persons aged 65 years and older in the Netherlands. In 1999, there were over 647,721 fall-related ED visits in the UK for persons aged 60 or older, leading to 204,424 hospital admissions (Scuffham et al., 2003).

Close et al. documented healthcare use of older fallers ( $\geq 70$ years old) in Australia. From 2008 through 2010, older fallers constituted 17\% of all ED visits, which led to hospital admission in $42.7 \%$ of the cases, after hospitalization $9.5 \%$ became first-time resident of long-term care facilities (Close et al., 2011).

\section{Predominant Injuries}

In 2006 there were 10,300 fatal and 2.6 million non-fatal fall-related injuries in the population aged $\geq 65$ in the US (Stevens et al., 2006). Accidental injury, often resulting from a fall, ranks as the ninth leading cause of death among people over 65 years of age in the US (Kochanek et al., 2011).

Older adults are more prone to injury than younger persons, and similar injury mechanisms will result in more severe consequences for the elderly. For instance, the increased fracture incidence at older age is partly attribu to osteoporosis. The most common injuries due to falls in persons aged 65 years or older in the Netherlands are superficial injuries, hip fractures, upper 
extremity fractures, and traumatic brain injury (Hartholt et al., 2010). About 30\% of people with a hip fracture will die in the following year, and many more will experience significant functional loss (Brauer et al., 2009). Data from recent studies in Europe and North America indicate that the incidence of hip fractures is declining (Brauer et al., 2009, Chevalley et al., 2007, Kannus et al., 2006, Leslie et al., 2009). This decline has been observed since 1985 (Leslie et al., 2009) and by some as early as 1950 (Melton et al., 1996). Having an explanation for this trend could be helpful in developing programs for further reduction of the hip fracture incidence rate. However, there seems yet to be no clear answer to this incidence decline. One of the most striking observations is the disparity in decline of the male and female incidence rates, Chevalley et al. reported no decrease in hip fracture rates between 1991 and 2000 in males in Switzerland (Chevalley et al., 2007), and Hartholt et al. reported a continuing increase in hip fracture rates in the oldest men aged 80 years and older in the Netherlands between 1980 and 2008 (Hartholt et al., 2011a). One explanation for this observation could be the lack of awareness and preventive measures against osteoporosis in men. However, the overall decline in hip fracture incidence rates observed in both males and females in the US and Canada cannot be explained by this (Brauer et al., 2009, Leslie et al., 2009). Several other explanations have been suggested such as improved nutrition status, 
increasing body weight, declining smoking rates, and hormone replacement therapy yet there is no definitive answer. A combination of all these factors is probably the reason for the lower incidence rate of hip fractures in western countries.

Traumatic brain injury is associated with serious consequences. Recent studies in the US (Faul, 2010), the Netherlands (Hartholt et al., 2011c), and Finland (Kannus et al., 2007) showed an increase in fall-related traumatic brain injury. Falls cause $60.7 \%$ of traumatic brain injuries among persons aged 65 years and older in the US (Faul, 2010). Rates for ED visits, hospitalization and death due to traumatic brain injury in the US all increased from 2002 to 2006, with hospitalization rates increasing from 67.6 to 90.7 per 100,000 in persons aged 65 or older (Faul, 2010). A similar increase in hospitalization rates after traumatic brain injury was also seen in the Netherlands (Hartholt et al., 2011c). A definite cause is yet unknown, the observed increase could in part be due to the increased mobility of the elderly, the implementation of new treatment guidelines, the increased use of radiographic imaging, or the rising life expectancy in western countries. 


\section{Health-Related Quality of Life}

In addition to the effects on morbidity and mortality as described above, falls result in a significant reduction in health-related quality of life and substantial functional impairment one year after sustaining a hip fracture (Boonen et al., 2004, Randell et al., 2000). Compared with the general older population, fallers with hip factures, upper extremity fractures or skull/brain injury all displayed a higher prevalence of functional problems. In a Dutch population-based study, patients aged 65 years or older who had sustained a hip fracture reported problems in all domains of the EuroQol-5D (EQ-5D), including mobility (90\% of patients), self-care (54\%), usual activities (73\%), pain/discomfort (69\%), anxiety/depression (28\%) and cognition (38\%) up to nine months after the fall (Hartholt et al., 2011b). Marottoli et al. studied physical function following a hip fracture in persons aged 65 and older; at baseline, $86 \%$ of patients could dress independently versus $49 \%$ at six months. Similarly, $90 \%$ could transfer independently versus $32 \%$ at six months; $75 \%$ could walk across a room independently versus $15 \%$ at six months; $63 \%$ could climb a flight of stairs versus $8 \%$ at six months; and $41 \%$ could walk one-half mile versus $6 \%$ at six months (Marottoli et al., 1992). Injury following a fall is associated with a decreased quality of life and poor functional outcome, in severe injuries these effects continue for a prolonged period of time. 


\section{Healthcare Costs}

In 2006 fall-related medical costs in the population aged $\geq 65$ years in the US amounted to US $\$ 19$ billion (equivalent to $€ 13.8$ billion) for non-fatal and US\$0.2 billion (€0.15 billion) for fatal injuries (Stevens et al., 2006). The estimated population aged $\geq 65$ in 2006 in the US was 37 million (Census-Bureau, 2010, ONS, 1999), which amounts to a per capita cost of US\$517 (€382). Between 2003 and 2007 the average annual cost for fall-related injuries in the Netherlands was US\$ 0.64 billion (€0.47 billion), in 2005 the population aged $\geq 65$ in the Netherlands was 2.3 million (CBS, 2011), which amounts to a per capita cost of US\$280 (€207). In 1999, the total cost to the UK government from unintentional falls in persons aged 60 or older was US $\$ 1.6$ billion (€1.15 billion) (Scuffham et al., 2003), the UK population aged $\geq 60$ in 1999 was 12.2 million (ONS, 1999) thus the per capita cost was approximately US\$130 (€96). In 2005 Roudsari et al., estimated the mean cost per fall-related hospitalization in the US to be US $\$ 17,483(€ 12,674)$, the mean cost per ED visit US\$236 ( $€ 171)$ and the mean cost per outpatient visit US\$412 (€299) (Roudsari et al., 2005). Between 2003 and 2007 the average cost per hip fracture in the Netherlands was US\$24,639 (€18,223), the cost per patient admitted to a hospital with traumatic brain injury after a fall was US\$19,309 (€14,281) and overall cost per fall US\$9,530 (€7,048) (Hartholt et al., 2011b). 


\section{Falls Prevention Initiatives}

Much effort has been put into prevention programs, assessing risk factors, such as previous falls, impaired balance and gait, and fall-risk-increasing drugs. There have been successful single intervention studies, implementing exercise programs which mainly consisted of muscle strengthening and balance exercises (Campbell et al., 1999a, Province et al., 1995), and a study featuring withdrawal of fall-risk-increasing drugs (FRIDs) (Campbell et al., 1999b). The withdrawal of FRIDs should place minimal burden on the healthcare system, fallers taking FRIDs are easily identified, and withdrawal is shown to be safely possible and effective for both cardiovascular and psychotropic drugs (van der Velde et al., 2007). Campbell et al. demonstrated how withdrawal of psychotropic medication significantly reduced falls; however, permanent withdrawal was difficult to achieve (Campbell et al., 1999b). There are also falls prevention programs with multiple interventions; these are called multifactorial intervention programs. The most common interventions featured in successful multifactorial intervention studies are exercise, medication review, an assessment of vision, hearing, cardiovascular function and psychological state with proper referrals, and an assessment of the home environment and assistive devices (Close et al., 1999, Davison et al., 2005, Jensen et al., 2002, Spice et al., 2009, Tinetti et al., 1994, AGS/BGS, 2010, AGS/BGS/AAOS, 
2001). Efficacy of such interventions varies, and in some multifactorial intervention studies no reduction in falls could be shown (de Vries et al., 2011, Mahoney et al., 2007). Thus there is room for improvement and further research concerning this complex problem. Identifying the population that will benefit most from falls-prevention programs and determining which components of multifactorial interventions are most effective could improve current results. With such a broad range of risk factors, falls-prevention is not a simple task.

\section{Discussion}

In this paper, different aspects of falls and the impact of falls on the elderly, healthcare systems, and society have been reviewed based on current literature. In the past decades there has been a growing awareness in western societies, concerning the increasing burden of falls. Although the mortality rate following a fall and the incidence rates of hip fractures have decreased, hospitalization rates for traumatic brain injury are increasing. The absolute number of falls and injury following a fall continues to rise, as do the costs. Factors which have reduced injury severity following a fall are preventative measures and treatment for osteoporosis, an improved nutrition status, 
increasing body weight, declining smoking rates, hormone replacement therapy, and more recently falls-prevention programs. Yet the decline in hip fracture rates is not explained by these factors alone, a definitive answer concerning the reduction in hip fracture rates could help us further in preventing fractures following falls. Falls affect a large proportion of the elderly population and have a substantial impact, with consequences such as higher morbidity and mortality rates, disability, fear of falling, social isolation, loss of independence, and institutionalization. Fall-related injuries and loss of function, quality of life and independence place a substantial burden on healthcare systems due to the large amount of visits to emergency departments, hospital admissions, admissions to long-term care and rehabilitation facilities, and other healthcare services needed. The elderly population in our society will continue to increase during the coming decades. This may be a reflection of the change in life style and the advances in public health and medical care, yet this will challenge us with rising healthcare budgets worldwide. 


\section{Funding}

This work was supported by a research grant from "the Netherlands

Organization for Health Research and Development" (ZonMw) [grant number 170.885.607].

\section{Conflict of Interest Statement}

The authors declare that there is no Conflict of Interest. 


\section{References}

AGS/BGS. 2010. Summary of the Updated American Geriatrics Society/British Geriatrics Society clinical practice guideline for prevention of falls in older persons. J Am Geriatr Soc 59: 148-57.

AGS/BGS/AAOS. 2001. Guideline for the prevention of falls in older persons. American Geriatrics Society, British Geriatrics Society, and American Academy of Orthopaedic Surgeons Panel on Falls Prevention. J Am Geriatr Soc 49: 664-72.

Boonen S, Autier P, Barette M, Vanderschueren D, Lips P, Haentjens P. 2004. Functional outcome and quality of life following hip fracture in elderly women: a prospective controlled study. Osteoporos Int 15: 87-94.

Brauer CA, Coca-Perraillon M, Cutler DM, Rosen AB. 2009. Incidence and mortality of hip fractures in the United States. Jama 302: 1573-9.

Campbell AJ, Robertson MC, Gardner MM, Norton RN, Buchner DM. 1999a. Falls prevention over 2 years: a randomized controlled trial in women 80 years and older. Age Ageing 28: 513-8.

Campbell AJ, Robertson MC, Gardner MM, Norton RN, Buchner DM. 1999b. Psychotropic medication withdrawal and a home-based exercise 
program to prevent falls: a randomized, controlled trial. J Am Geriatr Soc 47: 850-3.

CBS (2010) Kerncijfers van de bevolkingsprognose, 2010-2060. Centraal Bureau Statistiek 2010.

CBS. 2011. Bevolking; kerncijfers. Centraal Bureau voor de Statistiek (http://statline.cbs.nl/StatWeb/publication/?VW=T\&DM=SLNL\&PA=37296 ned\&D1=a\&D2=0,10,20,30,40,50,(I-1)-I\&HD=111128-

1323\&HDR=G1\&STB=T). Last accessed on November 20, 2011.

CDC (2004) Web-based Injury Statistics Query and Reporting System (WISQARS). IN CENTERS FOR DISEASE CONTROL AND PREVENTION, A. (Ed.).

Census-Bureau. 2010. Intercensal Estimates of the Resident Population by Sex and Age for the United States: April 1, 2000 to July 1, 2010. U.S. Census Bureau, Population Division.

Chevalley T, Guilley E, Herrmann FR, Hoffmeyer P, Rapin CH, Rizzoli R. 2007. [Incidence of hip fracture: reversal of a secular trend]. Rev Med Suisse 3: 1528-30, 1532-3.

Close J, Ellis M, Hooper R, Glucksman E, Jackson S, Swift C. 1999. Prevention of falls in the elderly trial (PROFET): a randomised controlled trial. Lancet 353: 93-7. 
Close JC, Lord SR, Antonova EJ, Martin M, Lensberg B, Taylor M, Hallen J, Kelly A. 2011. Older people presenting to the emergency department after a fall: a population with substantial recurrent healthcare use. Emerg Med J.

Davison J, Bond J, Dawson P, Steen IN, Kenny RA. 2005. Patients with recurrent falls attending Accident \& Emergency benefit from multifactorial intervention--a randomised controlled trial. Age Ageing 34: 162-8.

de Vries OJ, Peeters GM, Elders PJ, Muller M, Knol DL, Danner SA, Bouter LM, Lips P. 2011. Multifactorial intervention to reduce falls in older people at high risk of recurrent falls: a randomized controlled trial. Arch Intern Med 170: $1110-7$.

Faul M, Xu, L., Wald, M., and Coronado, V. 2010. Traumatic Brain Injury in the United States: Emergency Department Visits, Hospitalizations and Deaths 2002-2006. Centers for Disease Control and Prevention, National Center for Injury Prevention and Control: Atlanta.

Greenspan AI, Coronado VG, Mackenzie EJ, Schulman J, Pierce B, Provenzano G. 2006. Injury hospitalizations: using the nationwide inpatient sample. J Trauma 61: 1234-43. 
Hartholt KA, Oudshoorn C, Zielinski SM, Burgers PT, Panneman MJ, van Beeck EF, Patka P, van der Cammen TJ. 2011a. The epidemic of hip fractures: are we on the right track? PLoS One 6: e22227.

Hartholt KA, van Beeck EF, Polinder S, van der Velde N, van Lieshout EMM, Panneman MJ, van der Cammen TJM, Patka P. 2011b. Societal consequences of falls in the older population: injuries, healthcare costs, and long-term reduced quality of life. J Trauma 71: 748-53.

Hartholt KA, van der Velde N, Looman CW, van Lieshout EMM, Panneman MJ, van Beeck EF, Patka P, van der Cammen TJM. 2010. Trends in fallrelated hospital admissions in older persons in the Netherlands. Arch Intern Med 170: 905-11.

Hartholt KA, Van Lieshout EMM, Polinder S, Panneman MJ, Van der Cammen TJM, Patka P. 2011c. Rapid increase in hospitalizations resulting from fall-related traumatic head injury in older adults in The Netherlands 19862008. J Neurotrauma 28: 739-44.

Jensen J, Lundin-Olsson L, Nyberg L, Gustafson Y. 2002. Fall and injury prevention in older people living in residential care facilities. A cluster randomized trial. Ann Intern Med 136: 733-41.

Kannus P, Niemi S, Parkkari J, Palvanen M, Sievanen H. 2007. Alarming rise in fall-induced severe head injuries among elderly people. Injury 38: 81-3. 
Kannus P, Niemi S, Parkkari J, Palvanen M, Vuori I, Jarvinen M. 2006. Nationwide decline in incidence of hip fracture. $J$ Bone Miner Res 21: 1836-8.

Kochanek KD, Xu JQ, Murphy SL, al. e (2011) Deaths: Preliminary data for 2009., Hyattsville, MD: National Center for Health Statistics.

Leipzig RM, Cumming RG, Tinetti ME. 1999a. Drugs and falls in older people: a systematic review and meta-analysis: I. Psychotropic drugs. J Am Geriatr Soc 47: 30-9.

Leipzig RM, Cumming RG, Tinetti ME. 1999b. Drugs and falls in older people: a systematic review and meta-analysis: II. Cardiac and analgesic drugs. J Am Geriatr Soc 47: 40-50.

Leslie WD, O'Donnell S, Jean S, Lagace C, Walsh P, Bancej C, Morin S, Hanley DA, Papaioannou A. 2009. Trends in hip fracture rates in Canada. Jama 302: 883-9.

Mahoney JE, Shea TA, Przybelski R, Jaros L, Gangnon R, Cech S, Schwalbe A. 2007. Kenosha County falls prevention study: a randomized, controlled trial of an intermediate-intensity, community-based multifactorial falls intervention. J Am Geriatr Soc 55: 489-98.

Marottoli RA, Berkman LF, Cooney LM, Jr. 1992. Decline in physical function following hip fracture. J Am Geriatr Soc 40: 861-6. 
Melton LJ, 3rd, Atkinson EJ, Madhok R. 1996. Downturn in hip fracture incidence. Public Health Rep 111: 146-50; discussion 151.

Nevitt MC, Cummings SR, Kidd S, Black D. 1989. Risk factors for recurrent nonsyncopal falls. A prospective study. Jama 261: 2663-8.

ONS. 1999. Key Population and Vital Statistics - Annex A1: National populations at Mid-1999 by single year of age and sex. No. 26, 1999 Edition. Office for National Statistics.

Province MA, Hadley EC, Hornbrook MC, Lipsitz LA, Miller JP, Mulrow CD, Ory MG, Sattin RW, Tinetti ME, Wolf SL. 1995. The effects of exercise on falls in elderly patients. A preplanned meta-analysis of the FICSIT Trials. Frailty and Injuries: Cooperative Studies of Intervention Techniques. Jama 273: 1341-7.

Randell AG, Nguyen TV, Bhalerao N, Silverman SL, Sambrook PN, Eisman JA. 2000. Deterioration in quality of life following hip fracture: a prospective study. Osteoporos Int 11: 460-6.

Roudsari BS, Ebel BE, Corso PS, Molinari NA, Koepsell TD. 2005. The acute medical care costs of fall-related injuries among the U.S. older adults. Injury 36: 1316-22. 
Scuffham P, Chaplin S, Legood R. 2003. Incidence and costs of unintentional falls in older people in the United Kingdom. J Epidemiol Community Health 57: 740-4.

Spice CL, Morotti W, George S, Dent TH, Rose J, Harris S, Gordon CJ. 2009. The Winchester falls project: a randomised controlled trial of secondary prevention of falls in older people. Age Ageing 38: 33-40.

Stevens JA, Corso PS, Finkelstein EA, Miller TR. 2006. The costs of fatal and non-fatal falls among older adults. Inj Prev 12: 290-5.

Tinetti ME, Baker DI, McAvay G, Claus EB, Garrett P, Gottschalk M, Koch ML, Trainor K, Horwitz RI. 1994. A multifactorial intervention to reduce the risk of falling among elderly people living in the community. $N$ Engl J Med 331: 821-7.

Tinetti ME, Speechley M, Ginter SF. 1988. Risk factors for falls among elderly persons living in the community. N Engl J Med 319: 1701-7.

van der Velde N, Stricker BH, Pols HA, van der Cammen TJ. 2007. Risk of falls after withdrawal of fall-risk-increasing drugs: a prospective cohort study. Br J Clin Pharmacol 63: 232-7.

Vincent GK, Velkoff VA (2010) THE NEXT FOUR DECADES, The Older Population in the United States: 2010 to 2050. IN U.S. CENSUS BUREAU, W., DC (Ed.), Current Population Reports. 
WHO. 2011. Global Health Data Repository: life expectancy.

Woolcott JC, Richardson KJ, Wiens MO, Patel B, Marin J, Khan KM, Marra CA.

2009. Meta-analysis of the impact of 9 medication classes on falls in elderly persons. Arch Intern Med 169: 1952-60. 